\title{
Reflections on the North Central Community Gardens Branch Out Project
}

Food as a Tool for Social Change

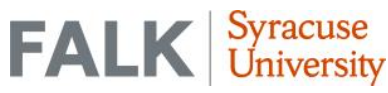

\author{
Maegan Krajewski* \\ University of Regina
}

Submitted February 1, 2021 / Published online September 16, 2021

Citation: Krajewski, M. (2021). Reflections on the North Central Community

Gardens Branch Out Project. Journal of Agriculture, Food Systems, and Community

Development, 10(4), 51-54. https://doi.org/10.5304/jafscd.2021.104.027

Copyright (C) 2021 by the Author. Published by the Lyson Center for Civic Agriculture and Food Systems. Open access under CC-BY license.

\begin{abstract}
The North Central Community Gardens, an urban agriculture initiative of the North Central Community Association in Regina, Saskatchewan, Canada, introduced the Branch Out Project in the summer of 2020. The project's purpose was to expand the North Central Community Gardens, which already consisted of three locations, onto additional schoolyard and backyard land. Despite-or perhaps because of - the COVID-19 pandemic, the first season of the project resulted in the construction of eight new gardens and has positively impacted food access, community engagement, and knowledge development and exchange. The goals of this commentary are two-fold: (1) to provide insight into the process of community garden expansion, with the hopes of benefiting other practitioners; and (2) to contribute to an understanding of the possibilities, challenges, and impacts of community gardens in general, and community garden expansion in particular, as a counter-neoliberal food sovereignty practice.
\end{abstract}

\section{Keywords}

Community Garden, Urban Agriculture, Counter-Neoliberalization, Community Food Systems, Food Sovereignty, Canada

* Maegan Krajewski, Graduate Student, Department of Sociology \& Social Studies, University of Regina; krajewsm@uregina.ca

\section{Funding Disclosure}

This research is funded by a SSHRC CGS Master's Scholarship and a Regina Public Interest Research Group Graduate Research Grant.

\section{Author Note}

The University of Regina research ethics board determined that the author's employment with the NCCA was not a conflict of interest with her research on the Branch Out Project. 


\title{
"When does urban farming pose a challenge to neoliberalization?" \\ —Weissman, 2015, p. 360
}

\begin{abstract}
A $S$ with all work that is critical of alternative food system initiatives, this quotation makes us rigor-

ously question whether our efforts to confront the injustices of neoliberal capitalism are truly effective or whether we may be reproducing inequalities identical to those of the conventional food system. Since first engaging with this question, I have worked as the Community Garden Coordinator for the North Central Community Association (NCCA), located in Regina, Saskatchewan, Canada, for five seasons, and am concurrently a graduate student at the University of Regina. As a scholar-practitioner, I strive to carry this question with me in my daily work, aiming not only to facilitate urban agriculture but also to join a movement of co-conspiring with community members to (1) reconnect with the means of food production; (2) establish avenues for greater community control of how food is produced, acquired, and consumed; (3) organize more equitable labor relations through which to grow, process, and distribute food; and (4) advocate for the realization of food as an entitlement.
\end{abstract}

\section{An Introduction to the Branch Out Project}

With these goals in mind, the North Central Community Gardens (NCCG) debuted the Branch Out Project (BOP) in the summer of 2020. The NCCG, an urban agriculture initiative of the NCCA, introduced BOP after several years of listening to community members' desires for increased access to garden space. The project's purpose was to expand the NCCG, which already consisted of three open-access locations, onto additional schoolyard and backyard land. Despite-or perhaps, in some ways, because of (Mejia et al., 2020) - the COVID-19 pandemic, the first season of BOP resulted in the construction of eight new gardens. However, this project is not simply about building gardens, nor is it suggesting that the solution to poverty, inadequate food access, and insufficient public resources is that the people who suffer most from these injustices must, as the saying goes, pull themselves up by their bootstraps. Rather, the project strives to provide anyone with the ability to grow fresh produce for themselves and their community, and in doing so, increase the community's capacity for food sovereignty within a grassroots system. When they join BOP, participants become part of the NCCG network, agreeing to tend to their new garden and provide half of their produce to the NCCG in exchange for access to the initial resources to construct the garden, ongoing support from the coordinator and NCCG volunteers, and the availability of additional resources throughout each growing season.

Participants in BOP were selected following a survey that allowed respondents to indicate their interest in working with the NCCG to establish a new backyard or schoolyard garden. I then worked with the participants and a team of volunteers to construct and install the new gardens. Participants were invited to partake in a post-season interview to share their experiences and shed insight on the impacts of the program. Throughout the process of implementing BOP, several lessons were learned regarding both the practice and theoretical implications of community garden expansion.

\section{The Survey}

The survey was distributed via the NCCG Facebook page on July $8^{\text {th }}, 2020$, and contained three parts. The first section asked participants to respond to a series of questions about their experience with and perceptions of the existing gardens. The second consisted of demographic questions. The third invited respondents to indicate their interest in having a new garden established. Consistent with much of the existing literature on community gardening, survey responses $(\mathrm{N}=21)$ indicated that the existing gardens 
provide an array of benefits to a diverse group of community members (Aptekar, 2015; Baker, 2004; Blake \& Cloutier-Fisher, 2009; Drake \& Lawson, 2015; McClintock, 2014).

For all garden-facilitated activities in which they had previously participated, including planting days, workshops, drop-in volunteer hours, day camp field trips, harvest stands, and more, all respondents report having had either a slightly positive or very positive experience. Of those who responded, 100\% agreed to some extent that they consume more fresh produce because of the community gardens; $100 \%$ agreed to some extent that they have more control over what they eat; over $94 \%$ agreed to some extent that they have more knowledge about gardening; over $88 \%$ agreed to some extent that they spend less money on food; and over $84 \%$ agreed to some extent that they are more physically active. Additionally, $100 \%$ agreed to some extent that they have met new people; $100 \%$ agreed to some extent that they have more interaction with the land; 95\% agreed to some extent that they have contributed their skills, knowledge, or time to North Central; over 94\% agreed to some extent that they spend more time outside in the summer; and over $84 \%$ agreed to some extent that they feel safer in North Central. These findings echo conclusions found elsewhere (Drake \& Lawson, 2015) that community gardens have noticeable and valuable impacts on food access, education, and community engagement. In the final section of the survey, 11 respondents indicated an interest in volunteering their own yard for the community garden expansion project or a schoolyard with which they were affiliated.

\section{Community Garden Expansion}

Community garden projects often struggle to secure the funding necessary to sustain themselves, let alone expand (Drake \& Lawson, 2015; Ghose \& Pettygrove, 2014). In 2020, I was able to mobilize my privilege as a scholar-practitioner to secure a Social Sciences \& Humanities Research Council of Canada Master's Scholarship as well as a Regina Public Interest Research Group Graduate Research Grant, which provided the initial funding necessary for the first phase of construction. This phase consisted of building, filling with soil, and seeding three backyard gardens and one school garden.

After announcing the completion of this phase on Facebook, and having the story picked up by local print media and radio, the nonprofit organization Street Culture Project became interested in BOP. Having many of the same mandates as the NCCA, the two organizations partnered to implement a second phase, consisting of three additional backyard gardens and one additional schoolyard garden. Street Culture Project provided building materials, soil, and labor power for this phase. All eight new gardens were constructed with the involvement of residents, teachers, parent-teacher association members, and additional volunteers from within the community.

Although the new gardens were installed too late in the season to achieve maximum food production, they have already demonstrated a myriad of benefits, as articulated in interviews with participants. Patricia, whose new garden is accessible from the back alley and was harvested by herself and passersby, emphasized the impacts on both community connection and improved food access: "people like it back there, that garden, and when they see me back there and watering it, you know, people are driving by and then they're like 'yeah, good job!"' Similarly, Jade pointed to additional time spent outside, connections with people that he otherwise would not have met, and money saved on grocery shopping as key outcomes, explaining, for example, "we weren't buying as much grocery store produce, so I definitely see the change." The new gardens also contributed a large quantity of produce to a September harvest stand, where it was distributed for free to community members.

\section{Conclusion}

The first season of BOP illustrates the desire for increased access to community gardening, how this expansion can be implemented as a collaborative community-based project, and the multiple benefits 
that such a project can have. Although the project is in its initial stages, with more expansion planned for the 2021 season, BOP has already provided increased access to productive land for the NCCG, greater engagement of community members, larger quantities of fresh produce available for distribution throughout the community, additional knowledge development and exchange, and many other positive outcomes. However, if BOP is to genuinely "pose a challenge to neoliberalization" (Weissman, 2015, p. 360 ), the project must continue to focus on questions of access to the means of production; the community's capacity to have control of food production, acquisition, and consumption; equitable labor relations; and food as an entitlement. Moving forward, BOP must remain resistant to the anti-politics of bootstrap individualization and personal consumption, and instead actively pursue the collectivization of a community-oriented food system.

\section{Acknowledgments}

I would like to acknowledge and extend my gratitude to each of the participants, volunteers, and funders of the Branch Out Project. I would also like to thank my graduate supervisor, Dr. JoAnn Jaffe, for her support of this research. I conduct this work in the memory of Dr. Evan Weissman, whose mentorship will continue to inspire us to use food as a tool for social change.

\section{References}

Aptekar, S. (2015). Visions of public space: Reproducing and resisting social hierarchies in a community garden. Sociological Forum, 30(1), 209-227. https://doi.org/10.1111/socf.12152

Baker, L. E. (2004). Tending cultural landscapes and food citizenship in Toronto's community gardens. The Geographical Review, 94(3), 305-325. https://doi.org/10.1111/j.1931-0846.2004.tb00175.x

Blake, A. \& Cloutier-Fisher, D. (2009). Backyard bounty: Exploring the benefits and challenges of backyard garden sharing projects. Local Environment, 14(9), 797-807. https://doi.org/10.1080/13549830903166438

Drake, L. \& Lawson, L. J. (2015). Results of a US and Canada community garden survey: Shared challenges in garden management amid diverse geographical and organizational contexts. Agriculture and Human Values, 32, $241-254$. https://doi.org/10.1007/s10460-014-9558-7

Ghose, R. \& Pettygrove, M. (2014). Actors and networks in urban community garden development. Geoforum, 53, 93101. https://doi.org/10.1016/j.geoforum.2014.02.009

Mejia, A., Bhattacharya, M., Nigon-Crowley, A., Kirkpatrick, K., \& Katoch, C. (2020). Community gardening during times of crisis: Recommendations for community-engaged dialogue, research, and praxis. Journal of Agriculture, Food Systems, and Community Development, 10(1), 13-19. https://doi.org/10.5304/jafscd.2020.101.006

McClintock, N. (2014). Radical, reformist, and garden-variety neoliberal: Coming to terms with urban agriculture's contradictions. Local Environment, 19(2), 147-171. https://doi.org/10.1080/13549839.2012.752797

Weissman, E. (2015). Entrepreneurial endeavors: (Re)producing neoliberalization through urban agriculture youth programming in Brooklyn, New York. Environmental Education Research, 21(3), 351-364.

https://doi.org/10.1080/13504622.2014.993931 